\title{
Type 2 Diabetes and ADP Receptor Blocker Therapy
}

\author{
Matej Samoš, ${ }^{1}$ Marián Fedor, ${ }^{2}$ František Kovář, ${ }^{1}$ Michal Mokáň, ${ }^{1}$ Tomáš Bolek, ${ }^{1}$ \\ Peter Galajda, ${ }^{1}$ Peter Kubisz, ${ }^{2}$ and Marián Mokán̆ ${ }^{1}$ \\ ${ }^{1}$ Department of Internal Medicine I, Jessenius Faculty of Medicine in Martin, Comenius University in Bratislava, \\ 03659 Martin, Slovakia \\ ${ }^{2}$ National Center of Hemostasis and Thrombosis, Department of Hematology and Blood Transfusion, Jessenius Faculty of \\ Medicine in Martin, Comenius University in Bratislava, 03659 Martin, Slovakia
}

Correspondence should be addressed to Matej Samoš; matej.samos@gmail.com

Received 15 July 2015; Accepted 4 October 2015

Academic Editor: Andreas Melidonis

Copyright (C) 2016 Matej Samoš et al. This is an open access article distributed under the Creative Commons Attribution License, which permits unrestricted use, distribution, and reproduction in any medium, provided the original work is properly cited.

Type 2 diabetes (T2D) is associated with several abnormalities in haemostasis predisposing to thrombosis. Moreover, T2D was recently connected with a failure in antiplatelet response to clopidogrel, the most commonly used ADP receptor blocker in clinical practice. Clopidogrel high on-treatment platelet reactivity (HTPR) was repeatedly associated with the risk of ischemic adverse events. Patients with T2D show significantly higher residual platelet reactivity on ADP receptor blocker therapy and are more frequently represented in the group of patients with HTPR. This paper reviews the current knowledge about possible interactions between T2D and ADP receptor blocker therapy.

\section{Introduction}

Type 2 diabetes (T2D) is associated with several abnormalities in haemostasis, such as higher platelet reactivity [1, 2], endothelial dysfunction [3], and hypercoagulation and abnormalities in fibrinolysis [4], predisposing to thrombosis. ADP receptor blocker therapy is crucial in acute coronary syndrome (ACS) and postpercutaneous coronary intervention (PCI) patients to prevent future thrombotic events. According to current European Society of Cardiology and American Heart Association Clinical Practice Guidelines [57] ADP receptor blocker therapy should be administrated in all ST-elevation myocardial infarction (STEMI) and non-STelevation myocardial infarction (NSTEMI)/unstable angina (UA) patients, while in STEMI patients undergoing primary PCI new ADP receptor blockers (prasugrel, ticagrelor) should be preferred; in patients with NSTEMI/UA prasugrel should be used just when coronary anatomy is already known and a decision to perform PCI has been already established. Otherwise, ticagrelor or clopidogrel should be administrated. Moreover, these recommendations should be fully applicable in patients with as well as without T2D. Nevertheless, T2D was recently associated with a failure in antiplatelet response to clopidogrel $[8,9]$ which remains the most commonly used
ADP receptor blocker in clinical practice [10]. Importantly, clopidogrel high on-treatment platelet reactivity (HTPR) was consistently associated with the risk of ischemic adverse events. This paper reviews the current approaches of ADP receptor blocker therapy in $\mathrm{T} 2 \mathrm{D}$ patients.

\section{Clopidogrel and Its Resistance in T2D Patients}

Thienopyridine clopidogrel is an oral irreversible P2Y12 ADP receptor blocker. This prodrug requires oxidation by the hepatic cytochrome P450 system to generate an active metabolite. After absorption, an estimated $85 \%$ of the prodrug is hydrolysed by esterases into an inactive form, leaving only $15 \%$ of clopidogrel available for transformation to the active metabolite, which irreversibly and selectively inactivates P2Y12 ADP receptor and inhibits ADP-induced platelet aggregation [11]. The introduction of clopidogrel by the CURE study in patients with ACS [12] significantly improved the clinical outcome compared with patients treated with aspirin alone. Similar outcome was subsequently obtained in post-PCI patients $[13,14]$. However, the antiplatelet effect of clopidogrel varies among individuals. 
TABLE 1: ADP receptor blockers in current clinical practice.

\begin{tabular}{|c|c|c|c|c|c|c|}
\hline Drug & $\begin{array}{c}\text { Route of } \\
\text { administration }\end{array}$ & Bioavailability & $\begin{array}{l}\text { Receptor } \\
\text { inhibition }\end{array}$ & $\begin{array}{c}\text { Time to peak } \\
\text { platelet } \\
\text { inhibition }\end{array}$ & Clinical application & $\begin{array}{c}\text { Interactions with } \\
\mathrm{T} 2 \mathrm{D}\end{array}$ \\
\hline Clopidogrel & Oral & Prodrug & Irreversible & Highly variable & $\begin{array}{c}\text { PCI, arterial } \\
\text { interventions, ACS, } \\
\text { stroke, and secondary } \\
\text { prevention }\end{array}$ & Repeatedly proven \\
\hline Prasugrel & Oral & Prodrug & Irreversible & 2 hours & ACS with PCI & $\begin{array}{l}\text { Not explicitly } \\
\text { proven }\end{array}$ \\
\hline Ticagrelor & Oral & Direct-acting & Reversible & 2 hours & ACS & Probably none \\
\hline Cangrelor & Intravenous & Direct-acting & Reversible & 30 minutes & PCI & Not studied \\
\hline
\end{tabular}

ACS: acute coronary syndromes, PCI: percutaneous coronary intervention, T2D: type 2 diabetes.

As mentioned previously, there are a growing number of data pointing to the failure in antiplatelet responses to clopidogrel which is specifically associated with insulin resistance and T2D $[8,9,15]$. These reports are based on ex vivo testing of platelet reactivity on clopidogrel therapy, as well as on subanalysis of clinical trials with clopidogrel. In these trials patients with T2D on clopidogrel therapy had worse clinical course and increased incidence of stent thrombosis $[8,9,15-19]$. The exact mechanism of this phenomenon remains currently unknown. However, the mechanism of poor clopidogrel response in T2D patients is probably multifactorial. T2D per se increases the platelet reactivity to ADP. Insulin could reduce the platelet aggregation by inhibiting the P2Y12 pathway through insulin receptors [20]. Insulin resistance might upregulate the P2Y12 ADP receptor, which is associated with clopidogrel resistance [21,22]. An absolute or a relative lack of insulin was previously associated with increased P2Y12 signalling capacity. Moreover, this pathway appears to be in patients with T2D less sensitive to P2Y12 inhibition [23]. On the other hand, T2D may also interact with clopidogrel metabolism. T2D is already known to modulate cytochrome P450 activity in humans and in animal models [24-26]. Erlinge et al. [8] studied the prevalence and mechanism of antiplatelet failure to clopidogrel in T2D patients and in nondiabetic individuals. This double blinded study randomized totally 110 patients already treated with aspirin to clopidogrel $(600 \mathrm{mg}$ loading dose followed by a maintenance dose of $75 \mathrm{mg}$ ) or prasugrel $(60 \mathrm{mg}$ loading dose followed by daily maintenance dose of $10 \mathrm{mg}$ ) for a period of 28 days. Results of the study showed significantly higher incidence of HTPR in patients treated with clopidogrel compared to prasugrel. Diabetic patients were more frequently represented in the group with HTPR. Moreover, the HTPR was in T2D patients connected to the administration of clopidogrel. When compared with nondiabetic patients, patients with diabetes had significantly lower concentrations of clopidogrel active metabolite measured two hours after a loading dose administration $(p<0.01)$ and also on 29th day of maintenance dose usage $(p<0.01)$. It is interesting that, in this study, platelets of diabetic patients with HTPR responded well to ex vivo administration of the active clopidogrel metabolite. This observation indicates a low level of resistance on platelet P2Y12 ADP receptor and supports a potential interaction between T2D and pharmacokinetic processes of clopidogrel metabolism.

Angiolillo et al. [9] studied platelet function in diabetic and nondiabetic patients treated with aspirin and clopidogrel. Blood samples were taken after loading dose administration and on chronic therapy. The authors found significantly higher residual platelet reactivity in T2D patients both prior to clopidogrel administration and 24 hours after clopidogrel loading dose administration. In addition, the authors found a significantly higher number of patients with clopidogrel HTPR among patients with T2D. It is already known that HTPR is an independent predictor of cardiovascular events [9] and platelet reactivity on clopidogrel therapy higher than $50 \%$ was repeatedly associated with higher risk of coronary events after PCI $[17,18,27]$.

The worse clinical outcome and an increased risk of ischemic events in clopidogrel-treated T2D patients were consistently demonstrated in the subanalysis of the CURE [12], CREDO [28], and Current-OASIS 7 [29] trials. These data indirectly support an incomplete response to clopidogrel associated with T2D. Additionally, Iakovou et al. [19] in an analysis of data from a prospective observational study showed that T2D is an independent predictor of stent thrombosis, despite dual antiplatelet therapy in patients after successful implantation of drug eluting stents. High frequency of clopidogrel HTPR led to the introduction of new ADP receptor blockers with more favourable pharmacodynamic profile to clinical practice.

\section{Prasugrel: New ADP Receptor Blocker in T2D Patients}

Prasugrel (Table 1) is a new thienopyridine P2Y12 ADP receptor blocker, recently introduced to clinical practice in patients with ACS and planned PCI. Prasugrel compared to clopidogrel offers more consistent inhibition of P2Y12 ADP receptor and has a lower intraindividual variability in efficacy. Prasugrel was extensively tested in the TRITON-TIMI 38 trial [30] which randomized 13608 patients with ACS to clopidogrel or prasugrel. These patients were treated from 6 to 15 months. In this trial 3146 of patients had T2D; 776 patients were treated with insulin. The primary "endpoint" of this study was significantly decreased by prasugrel in nondiabetic group $(9.2 \%$ 
versus $10.6 \%, p<0.05)$, as well as in those with T2D $(12.2 \%$ versus $17.0 \%, p<0.001)$. Benefit of prasugrel administration was observed consistently in insulin-treated patients $(14.3 \%$ versus $22.2 \%, p<0.01$ ), as well as in T2D patients without insulin therapy $(11.5 \%$ versus $15.3 \%, p<0.01)$. Prasugrel significantly reduced the incidence of myocardial infarction (MI) by $18 \%$ in nondiabetic subjects and by $40 \%$ in subjects with T2D. Moreover, this study showed a significant reduction of stent thrombosis by prasugrel in the overall group $(0.9 \%$ versus $2.0 \%)$, as well as in T2D patients $(2.0 \%$ versus $3.5 \%)$. Nevertheless, major bleeding events not associated with coronary artery bypass graft surgery occurred overall significantly more often in patients treated with prasugrel, compared to clopidogrel (2.4 versus $1.8 \%)$. In summary, throughout the study, the greatest benefit of prasugrel therapy was observed preferentially in T2D patients, in whom prasugrel significantly reduced the risk of ischemic events, including the risk of recurrent $\mathrm{MI}$ and the risk of stent thrombosis, without increasing the risk of serious bleeding.

On the other hand, the efficacy of prasugrel is not so convincing in patients who do not undergo invasive coronary revascularization. The TRIOLOGY ACS study [31] — a double blind, randomized prospective trial involving 7243 patientsfailed to proof the significant reduction of the primary endpoint with prasugrel (10 mg daily) compared to clopidogrel (75 mg daily). Similar bleeding risk was observed in both groups of patients. In this study, $37.7 \%$ of prasugrel-treated and $38.3 \%$ of clopidogrel-treated patients had a history of T2D. Although the subanalysis of T2D patients was not reported specifically, generally there was no significant difference in the hazard ratio for primary endpoint in T2D patients compared to nondiabetic individuals (17.8\% versus $11.5 \%$ in clopidogrel-treated patients, $20.4 \%$ versus $13.2 \%$ in prasugreltreated patients, resp.; $p=0.71)$. Nevertheless, in this study, reduced ADP blocker loading doses (30 $\mathrm{mg}$ of prasugrel and $300 \mathrm{mg}$ of clopidogrel) were administrated only in patients who underwent randomization within first 72 hours after the first medical contact and were not previously pretreated with ADP receptor blocker. Patients who did not undergo randomization within first 72 hours were treated with daily maintenance dose administration (i.e., loading dose was not administrated). This fact could influence the reduction of the primary endpoint of this study.

\section{Prasugrel Resistance: A New Phenomenon in Diabetic Patients with ACS?}

Prasugrel was repeatedly described as an effective drug for overcoming clopidogrel resistance [27, 32]. However, several recently published data reported an incomplete response to prasugrel. Prasugrel resistance might therefore become another problem in patients requiring ADP receptor blocker therapy. Silvano et al. described a rare case of resistance to both clopidogrel and prasugrel in nondiabetic patient with acute STEMI due to stent thrombosis [33]. In addition, results of recently published studies $[34,35]$ suggest that real prevalence of HTPR in prasugrel-treated patients may be higher than that which is traditionally considered. Bonello et al. [35] pointed out the fact that up to $25 \%$ of patients with ACS did not reach effective antiplatelet response even after 6-12 hours from prasugrel loading dose administration. There is no definite answer to the question of a possible relationship between T2D and the phenomenon of "prasugrel resistance." We have previously described a delayed antiplatelet response to prasugrel in two T2D patients undergoing primary PCI for acute STEMI [36]. Consequently, Alexopoulos et al. [37] reported in an observational study involving 77 patients with ACS undergoing PCI that platelet reactivity in prasugreltreated patients differed significantly by T2D status. By multivariable analysis, insulin-treated T2D was identified as the only predictor of high platelet reactivity $(p<0.01)$. The authors concluded that patients with insulin-treated T2D treated with prasugrel post-PCI have higher platelet reactivity than patients without T2D or noninsulin-treated diabetic patients. This observation supports the possible interaction between T2D and prasugrel HTPR. However, this possible interaction remains inadequately explained and further studies will be needed for the final clarification of this issue.

\section{Cangrelor: The New Member of the ADP Receptor Blockers Family}

Cangrelor (Table 1) is an intravenously administrated adenosine triphosphate analogue that binds reversibly and with high affinity to P2Y12 ADP receptor. It offers a highly effective inhibition of ADP-induced platelet aggregation immediately after administration and allows the restoration of platelet function within 1-2 hours of its discontinuation [38]. Cangrelor has been investigated in three clinical trials including a total of 24910 patients [39-41]. A meta-analysis of these studies [42] observed a 19\% risk reduction rate in periprocedural death, MI, ischemia-driven revascularization, and stent thrombosis, with a $39 \%$ risk reduction rate in stent thrombosis alone. The TIMI major and minor bleeds were increased, but there was no increase in the rate of transfusions. This new agent may be considered in ADP receptor blocker naïve patients undergoing PCI for ACS [6]. Recently, there is no study specifically investigating possible interactions between $\mathrm{T} 2 \mathrm{D}$ and antiplatelet response to cangrelor.

\section{Ticagrelor: A Safe and Effective ADP Receptor Blocker in T2D Patients?}

Ticagrelor (Table 1) is a new oral, direct reversible P2Y12 ADP receptor blocker which achieves a higher range of inhibition of platelet aggregation compared to clopidogrel [43]. The PLATO study [44] tested the efficacy of ticagrelor and clopidogrel in the prevention of cardiovascular events in patients with ACS (totally 18.624 patients enrolled). The incidence of the primary endpoint after 12 months of follow-up was significantly lower in patients treated with ticagrelor $(10.2 \%$ versus $12.3 \%, p<0.001)$; there was also a significant reduction of cardiovascular deaths and stent thrombosis in the subgroup of ticagrelor-treated post-PCI patients. Ticagrelor administration was not associated with an increased risk of serious bleeding. In the group of diabetic patients ticagrelor reduced the incidence of the primary endpoint, all-cause mortality, and the risk of stent thrombosis. Similar benefit of 


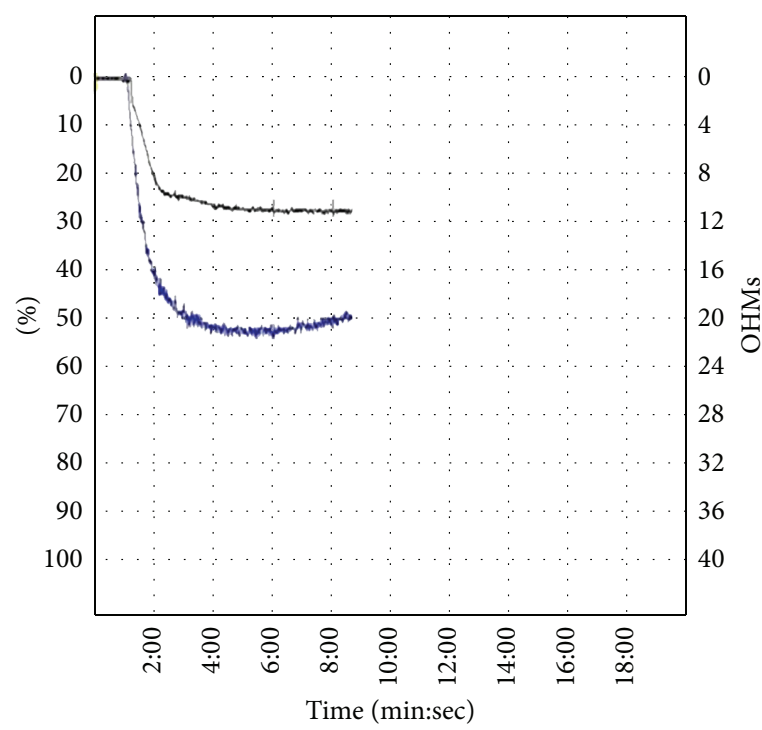

(a)

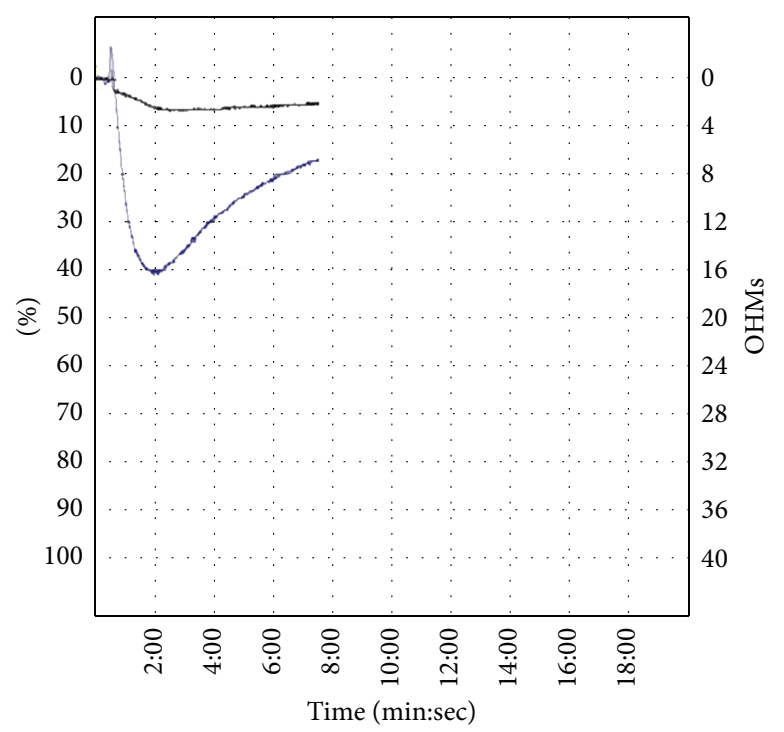

(b)

FIGURE 1: LTA with specific inducers (arachidonic acid: black curve, adenosine diphosphate: blue curve) showing difference between HTPR (a) and sufficient antiplatelet response (b) in T2D patient with acute ST-elevation myocardial infarction.

ticagrelor therapy was seen in insulin-treated T2D patients, as well as in diabetic patients without insulin therapy. In addition, Alexopoulos et al. [45] showed significantly lower platelet reactivity in ticagrelor-treated T2D patients compared to T2D patients treated with prasugrel. Moreover, in this single-center prospective randomized study none of the T2D patients was identified as a nonresponder for ticagrelor. Consistently, ticagrelor treatment was demonstrated to be effective and even superior to prasugrel [46] in high risk diabetic patients with ACS. These data suggest that ticagrelor may be a safe and effective ADP receptor blocker in T2D patients, which can ensure consistent platelet inhibition, without the risk of HTPR, together with a good safety profile.

\section{Detection of HTPR in Clinical Practice}

Assessing the individual level of platelet inhibition by implementing platelet function testing might help to identify patients with HTPR and therefore to reduce ischemic events. To assess the predictive level of platelet reactivity on ADP receptor blockers, numerous platelet function tests are currently available. Light transmission aggregometry (LTA) with specific inducer (adenosine diphosphate (ADP)) represents nowadays a "golden standard" in antiplatelet response testing. Maximal aggregation in response to ADP with LTA testing > $50 \%$ (Figure 1) had been associated with higher risk of ischemic events [47]. Second, vasodilator-stimulated phosphoprotein (VASP) phosphorylation flow cytometry assay represents a specific method for the assessment of ADP receptor blocker activity [48]. We have previously demonstrated that this assay is suitable for monitoring the ADP receptor blocker therapy in acute STEMI patients with primary PCI of culprit coronary lesion [49]. The advantage of this assay is its specificity for ADP receptor intracellular signaling pathway and sample stability. Nevertheless, instrumental and financial requirements may represent a possible limitation for the application of this assay in clinical practice. Third, several point-of-care assays are recently available. PFA-100 (Siemens Healthcare Diagnostics, Tarrytown, New York, USA) and Verify Now (Accumetries, San Diego, California, USA) assay methods-both based on modified aggregometry-allow quick platelet function testing in the setting of the intensive care units. Verify Now allows rapid assessment of platelet response on aspirin, P2Y12 ADP receptor antagonist, and glycoprotein IIb/IIIa antagonist treatment in one blood sample [50]. Bed site ADP receptor blockers testing may provide a rough guiding on how to proceed with treatment drugs and dosages, especially when both LTA and VASP phosphorylation assays are not available.

Although monitoring of ADP receptor blocker therapy is nowadays not generally recommended, this testing can significantly help to identify patients with HTPR. On the other hand, recently there is no definite answer to the question whether HTPR is a modifiable phenomenon. Several randomized studies trying to overcome HTPR with modified clopidogrel therapy guided by platelet function testing $[51,52]$ brought negative results. However, new antiplatelet agents were rarely used in these trials. Modified (increased) clopidogrel dosing, which was mostly used in these trials for overcoming the HPTR, failed to reduce the rate of major adverse cardiac events (cardiovascular death, nonfatal myocardial infarction, or stent thrombosis). The results of these randomized studies predominantly do not support a treatment strategy of high-dose clopidogrel in patients with HTPR and question the need of monitoring the on-treatment platelet reactivity in clinical practice. Nevertheless, a recently published observational study, which tested patients with planned PCI for stable angina or NSTE ACS [53], showed 
a reduced risk of adverse clinical events in HTPR patients with tailored intensified antiplatelet therapy. Thus, monitoring and tailoring the antiplatelet therapy might be beneficial in selected patients and deserve further investigation.

In summary, T2D seems to be associated with HTPR especially in clopidogrel-treated patients. Moreover, we have previously confirmed the association between HTPR and stent thrombosis in post-PCI patient with T2D [27]. Therefore, it is probably reasonable to routinely prefer new ADP receptor blockers over clopidogrel in T2D patients in order to ensure more effective platelet inhibition and prevent these serious thrombotic adverse events. Additionally, the subanalysis of T2D patients treated with new ADP receptor blockers did not reveal higher risk of serious bleeding. This indicates that the benefit/risk ratio is in favour of new antiplatelet agents. In case of choosing clopidogrel therapy in T2D patients, it seems to be reasonable to perform platelet function testing for the approval of sufficient on-treatment response. If this response is inadequate, the switch to new ADP receptor blocker therapy should be considered immediately. In addition, ticagrelor, in T2D patients with ACS, was demonstrated as more effective and superior even to prasugrel [46]. Thus this agent should be preferred especially in case of diabetics with acute coronary events. Nevertheless, the higher cost of medication, patient compliance, higher risk of bleeding, and other side effects should be also considered for a decision of ADP receptor blocker therapy strategy.

\section{Conclusion}

The above-mentioned evidence suggests that T2D is associated with clopidogrel HTPR. Patients with T2D show significantly higher residual platelet reactivity on clopidogrel therapy and are more frequently represented in the group of patients with clopidogrel HTPR. Moreover, several data reported that patients with insulin-treated T2D have higher residual platelet reactivity even on prasugrel therapy than patients without $\mathrm{T} 2 \mathrm{D}$ or noninsulin-treated diabetic patients. On the other hand, ticagrelor treatment was demonstrated to be effective and even superior to prasugrel in high risk diabetic patients with ACS and ticagrelor may be a safe and effective ADP receptor blocker in these patients. However, the relationship between T2D and ADP receptor blocker therapy is not fully explained and deserves further investigation.

\section{Disclosure}

Formal consent for this type of study is not required.

\section{Conflict of Interests}

The authors have no conflict of interests to declare.

\section{Acknowledgments}

This study was supported by the APVV Project (Slovak Research and Development Agency) 0222-11 and the research project of the Slovak Society of Cardiology 2012-2015.

\section{References}

[1] D. Aronson, Z. Bloomgarden, and E. J. Rayfield, "Potential mechanisms promoting restenosis in diabetic patients," Journal of the American College of Cardiology, vol. 27, no. 3, pp. 528-535, 1996.

[2] D. Tschoepe, P. Roesen, L. Kaufmann et al., "Evidence for abnormal platelet glycoprotein expression in diabetes mellitus," European Journal of Clinical Investigation, vol. 20, no. 2, pp. 166170, 1990.

[3] P. Kubisz, P. Chudý, J. Staško et al., "Circulating vascular endothelial growth factor in the normo- and/or microalbuminuric patients with type 2 diabetes mellitus," Acta Diabetologica, vol. 47, no. 2, pp. 119-124, 2010.

[4] P. Chudý, D. Kotuličová, J. Staško, and P. Kubisz, “The relationship among TAFI, t-PA, PAI-1 and F1 +2 in type 2 diabetic patients with normoalbuminuria and microalbuminuria," Blood Coagulation \& Fibrinolysis, vol. 22, no. 6, pp. 493-498, 2011.

[5] E. A. Amsterdam, N. K. Wenger, R. G. Brindis et al., "2014 AHA/ACC guideline for the management of patients with nonST-elevation acute coronary syndromes: executive summary: a report of the American College of Cardiology/American Heart Association Task Force on Practice Guidelines," Circulation, vol. 130, no. 25, pp. 2354-2394, 2014.

[6] M. Roffi, C. Patrono, J.-P. Collet et al., "2015 ESC guidelines for the management of acute coronary syndromes in patients presenting without persistent ST-segment elevation," European Heart Journal, 2015.

[7] P. G. Steg, S. K. James, D. Atar et al., "ESC Guidelines for the management of acute myocardial infarction in patients presenting with ST-segment elevation," European Heart Journal, vol. 33, no. 20, pp. 2569-2619, 2012.

[8] D. Erlinge, C. Varenhorst, O. Ö. Braun et al., "Patients with poor responsiveness to thienopyridine treatment or with diabetes have lower levels of circulating active metabolite, but their platelets respond normally to active metabolite added ex vivo," Journal of the American College of Cardiology, vol. 52, no. 24, pp. 1968-1977, 2008.

[9] D. J. Angiolillo, E. Bernardo, M. Sabaté et al., "Impact of platelet reactivity on cardiovascular outcomes in patients with type 2 diabetes mellitus and coronary artery disease," Journal of the American College of Cardiology, vol. 50, no. 16, pp. 1541-1547, 2007.

[10] J. Tang, M. P. Li, H. H. Zhou, and X. P. Chen, "Platelet inhibition agents: current and future P2Y12 receptor antagonists," Current Vascular Pharmacology, vol. 13, no. 5, pp. 566-577, 2015.

[11] P. Savi and J.-M. Herbert, "Clopidogrel and ticlopidine: P2Y ${ }_{12}$ adenosine diphosphate-receptor antagonists for the prevention of atherothrombosis," Seminars in Thrombosis and Hemostasis, vol. 31, no. 2, pp. 174-183, 2005.

[12] S. Yusuf, F. Zhao, S. R. Mehta, S. Chrolavicius, G. Tognoni, and K. K. Fox, "Effects of clopidogrel in addition to aspirin in patients with acute coronary syndromes without ST-segment elevation," The New England Journal of Medicine, vol. 345, no. 7, pp. 494-502, 2001.

[13] G. Patti, G. Colonna, V. Pasceri, L. L. Pepe, A. Montinaro, and G. Di Sciascio, "Randomized trial of high loading dose of clopidogrel for reduction of periprocedural myocardial infarction in patients undergoing coronary intervention: results from the ARMYDA-2 (Antiplatelet therapy for Reduction of MYocardial Damage during Angioplasty) Study," Circulation, vol. 111, no. 16, pp. 2099-2106, 2005. 
[14] E. I. Lev, R. Kornowski, H. Vaknin-Assa et al., "Effect of clopidogrel pretreatment on angiographic and clinical outcomes in patients undergoing primary percutaneous coronary intervention for ST-elevation acute myocardial infarction," The American Journal of Cardiology, vol. 101, no. 4, pp. 435-439, 2008.

[15] D. J. Angiolillo, P. Capranzano, B. Desai et al., "Impact of $\mathrm{P}_{2} \mathrm{Y}_{12}$ inhibitory effects induced by clopidogrel on platelet procoagulant activity in type 2 diabetes mellitus patients," Thrombosis Research, vol. 124, no. 3, pp. 318-322, 2009.

[16] T. Cuisset, C. Frere, J. Quilici et al., "High post-treatment platelet reactivity identified low-responders to dual antiplatelet therapy at increased risk of recurrent cardiovascular events after stenting for acute coronary syndrome," Journal of Thrombosis and Haemostasis, vol. 4, no. 3, pp. 542-549, 2006.

[17] P. A. Gurbel, K. P. Bliden, K. Guyer et al., "Platelet reactivity in patients and recurrent events post-stenting: results of the PREPARE POST-STENTING study," Journal of the American College of Cardiology, vol. 46, no. 10, pp. 1820-1826, 2005.

[18] P. A. Gurbel, K. P. Bliden, W. Samara et al., "Clopidogrel effect on platelet reactivity in patients with stent thrombosis: results of the CREST study," Journal of the American College of Cardiology, vol. 46, no. 10, pp. 1827-1832, 2005.

[19] I. Iakovou, T. Schmidt, E. Bonizzoni et al., "Incidence, predictors, and outcome of thrombosis after successful implantation of drug-eluting stents," The Journal of the American Medical Association, vol. 293, no. 17, pp. 2126-2130, 2005.

[20] I. A. Ferreira, K. L. Eybrechts, A. I. M. Mocking, C. Kroner, and J.-W. N. Akkerman, "IRS-1 mediates inhibition of Ca2 mobilization by insulin via the inhibitory G-protein Gi," The Journal of Biological Chemistry, vol. 279, no. 5, pp. 3254-3264, 2004.

[21] D. J. Angiolillo, E. Bernardo, C. Ramírez et al., "Insulin therapy is associated with platelet dysfunction in patients with type 2 diabetes mellitus on dual oral antiplatelet treatment," Journal of the American College of Cardiology, vol. 48, no. 2, pp. 298-304, 2006.

[22] D. J. Angiolillo, A. Fernandez-Ortiz, E. Bernardo et al., "Platelet function profiles in patients with type 2 diabetes and coronary artery disease on combined aspirin and clopidogrel treatment," Diabetes, vol. 54, no. 8, pp. 2430-2450, 2005.

[23] I. A. Ferreira, A. I. M. Mocking, M. A. H. Feijge et al., "Platelet inhibition by insulin is absent in type 2 diabetes mellitus," Arteriosclerosis, Thrombosis, and Vascular Biology, vol. 26, no. 2, pp. 417-422, 2006.

[24] S. Goldstein, A. Simpson, and P. Saenger, "Hepatic drug metabolism is increased in poorly controlled insulin-dependent diabetes mellitus," Acta Endocrinologica, vol. 123, no. 5, pp. 550556, 1990.

[25] T. Kudo, T. Shimada, T. Toda et al., "Altered expression of CYP in TSOD mice: a model of type 2 diabetes and obesity," Xenobiotica, vol. 39, no. 12, pp. 889-902, 2009.

[26] D. Patoine, M. Petit, S. Pilote, F. Picard, B. Drolet, and C. Simard, "Modulation of CYP3a expression and activity in mice models of type 1 and type 2 diabetes," Pharmacology Research \& Perspectives, vol. 2, no. 6, 2014.

[27] M. Samoš, R. Šimonová, F. Kovář et al., "Clopidogrel resistance in diabetic patient with acute myocardial infarction due to stent thrombosis," The American Journal of Emergency Medicine, vol. 32, no. 5, pp. 461-465, 2014.

[28] S. R. Steinhubl, P. B. Berger, J. Tift Mann III et al., "Early and sustained dual oral antiplatelet therapy following percutaneous coronary intervention: a randomized controlled trial," The Journal of the American Medical Association, vol. 288, no. 19, pp. 2411-2420, 2002.

[29] S. R. Mehta, J.-P. Bassand, S. Chrolavicius et al., "Dose comparisons of clopidogrel and aspirin in acute coronary syndromes," The New England Journal of Medicine, vol. 363, no. 10, pp. 930942, 2010.

[30] S. D. Wiviott, E. Braunwald, C. H. McCabe et al., "Prasugrel versus clopidogrel in patients with acute coronary syndromes," The New England Journal of Medicine, vol. 357, no. 20, pp. 20012015, 2007.

[31] M. T. Roe, P. W. Armstrong, K. A. A. Fox et al., "Prasugrel versus clopidogrel for acute coronary syndromes without revascularization," The New England Journal of Medicine, vol. 367, no. 14, pp. 1297-1309, 2012.

[32] D. Alexopoulos, G. Dimitropoulos, P. Davlouros et al., "Prasugrel overcomes high on-clopidogrel platelet reactivity poststenting more effectively than high-dose (150-mg) clopidogrel: the importance of cyp2c19*2 genotyping," JACC: Cardiovascular Interventions, vol. 4, no. 4, pp. 403-410, 2011.

[33] M. Silvano, C. F. Zambon, G. De Rosa et al., "A case of resistance to clopidogrel and prasugrel after percutaneous coronary angioplasty," Journal of Thrombosis and Thrombolysis, vol. 31, no. 2, pp. 233-234, 2011.

[34] G. Cayla, T. Cuisset, J. Silvain et al., "Prasugrel monitoring and bleeding in real world patients," The American Journal of Cardiology, vol. 111, no. 1, pp. 38-44, 2013.

[35] L. Bonello, M. Pansieri, J. Mancini et al., "High on-treatment platelet reactivity after prasugrel loading dose and cardiovascular events after percutaneous coronary intervention in acute coronary syndromes," Journal of the American College of Cardiology, vol. 58, no. 5, pp. 467-473, 2011.

[36] M. Samoš, M. Fedor, F. Kovář et al., "Prasugrel loading dose in diabetic patients with acute STEMI-always sufficiently effective? Observation in two cases and review of current knowledge," Cor et Vasa, vol. 56, no. 5, pp. e388-e395, 2014.

[37] D. Alexopoulos, C. Vogiatzi, K. Stavrou et al., "Diabetes mellitus and platelet reactivity in patients under prasugrel or ticagrelor treatment: an observational study," Cardiovascular Diabetology, vol. 14, article 68, 2015.

[38] R. F. Storey, K. G. Oldroyd, and R. G. Wilcox, “Open multicentre study of the P2T receptor antagonist AR-C69931MX assessing safety, tolerability and activity in patients with acute coronary syndromes," Thrombosis and Haemostasis, vol. 85, no. 3, pp. 401407, 2001.

[39] R. A. Harrington, G. W. Stone, S. McNulty et al., "Platelet inhibition with cangrelor in patients undergoing PCI," The New England Journal of Medicine, vol. 361, no. 24, pp. 2318-2329, 2009.

[40] D. L. Bhatt, A. M. Lincoff, C. M. Gibson et al., "Intravenous platelet blockade with cangrelor during PCI," The New England Journal of Medicine, vol. 361, no. 24, pp. 2330-2341, 2009.

[41] D. L. Bhatt, G. W. Stone, K. W. Mahaffey et al., "Effect of platelet inhibition with cangrelor during PCI on ischemic events," The New England Journal of Medicine, vol. 368, no. 14, pp. 1303-1313, 2013.

[42] P. G. Steg, D. L. Bhatt, C. W. Hamm et al., "Effect of cangrelor on periprocedural outcomes in percutaneous coronary interventions: a pooled analysis of patient-level data," The Lancet, vol. 382, no. 9909, pp. 1981-1992, 2013.

[43] R. F. Storey, S. Husted, R. A. Harrington et al., "Inhibition of platelet aggregation by AZD6140, a reversible oral $\mathrm{P}_{2} \mathrm{Y}_{12}$ 
receptor antagonist, compared with clopidogrel in patients with acute coronary syndromes," Journal of the American College of Cardiology, vol. 50, no. 19, pp. 1852-1856, 2007.

[44] L. Wallentin, R. C. Becker, A. Budaj et al., "Ticagrelor versus clopidogrel in patients with acute coronary syndromes," The New England Journal of Medicine, vol. 361, no. 11, pp. 1045-1057, 2009.

[45] D. Alexopoulos, I. Xanthopoulou, E. Mavronasiou et al., "Randomized assessment of ticagrelor versus prasugrel antiplatelet effects in patients with diabetes," Diabetes Care, vol. 36, no. 8, pp. 2211-2216, 2013.

[46] M. Laine, C. Frère, R. Toesca et al., “Ticagrelor versus prasugrel in diabetic patients with an acute coronary syndrome. A pharmacodynamic randomised study," Thrombosis and Haemostasis, vol. 111, no. 2, pp. 273-278, 2013.

[47] A. R. Harper and M. J. Price, "Platelet function monitoring and clopidogrel," Current Cardiology Reports, vol. 15, article 321, 2013.

[48] J. Geiger, J. Brich, P. Hönig-Liedl et al., "Specific impairment of human platelet $\mathrm{P} 2 \mathrm{Y}_{\mathrm{AC}} \mathrm{ADP}$ receptor-mediated signaling by the antiplatelet drug clopidogrel," Arteriosclerosis, Thrombosis, and Vascular Biology, vol. 19, no. 8, pp. 2007-2011, 1999.

[49] M. Fedor, M. Samoš, R. Šimonová et al., "Monitoring the efficacy of ADP inhibitor treatment in patients with acute STEMI post-PCI by VASP-P flow cytometry assay," Clinical and Applied Thrombosis/Hemostasis, vol. 21, no. 4, pp. 334-338, 2015.

[50] J. W. Smith, S. R. Steinhubl, A. M. Lincoff et al., "Rapid plateletfunction assay: an automated and quantitative cartridge-based method," Circulation, vol. 99, no. 5, pp. 620-625, 1999.

[51] M. J. Price, P. B. Berger, P. S. Teirstein et al., "Standard- vs highdose clopidogrel based on platelet function testing after percutaneous coronary intervention: the GRAVITAS randomized trial," The Journal of the American Medical Association, vol. 305, no. 11, pp. 1097-1105, 2011.

[52] J.-P. Collet, T. Cuisset, G. Rangé et al., "Bedside monitoring to adjust antiplatelet therapy for coronary stenting," The New England Journal of Medicine, vol. 367, no. 22, pp. 2100-2109, 2012.

[53] N. Paarup Dridi, P. I. Johansson, J. T. Lønborg et al., “Tailored antiplatelet therapy to improve prognosis in patients exhibiting clopidogrel low-response prior to percutaneous coronary intervention for stable angina or non-ST elevation acute coronary syndrome," Platelets, vol. 26, no. 6, pp. 521-529, 2015. 


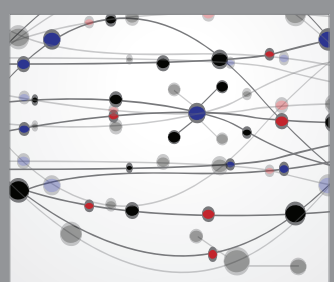

The Scientific World Journal
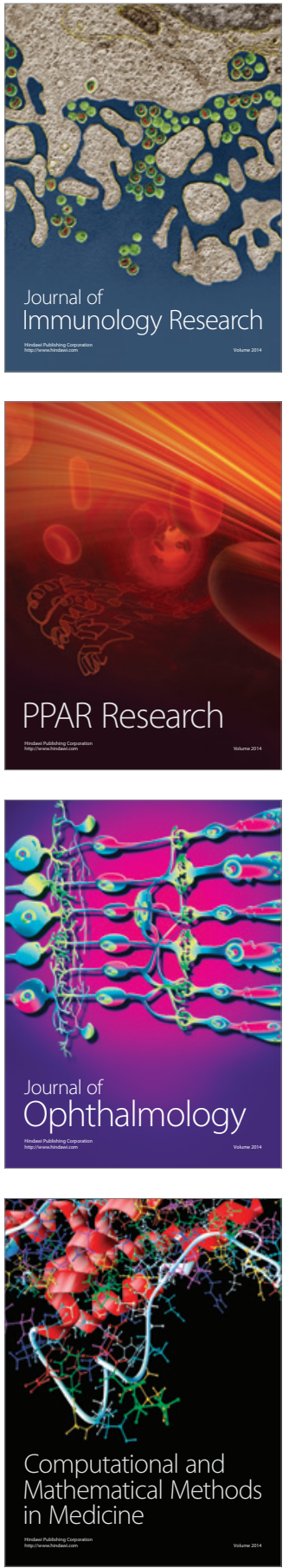

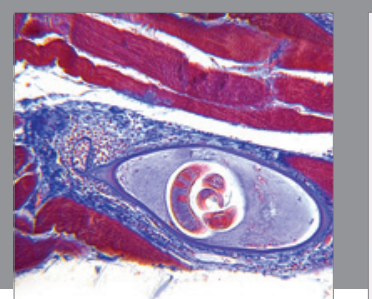

Gastroenterology Research and Practice

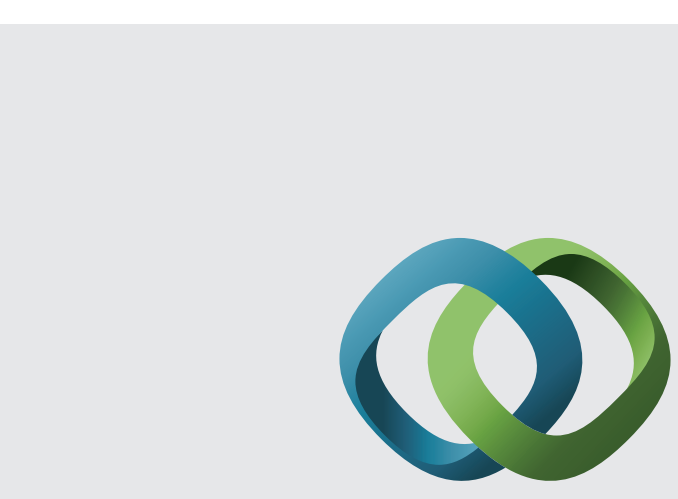

\section{Hindawi}

Submit your manuscripts at

http://www.hindawi.com
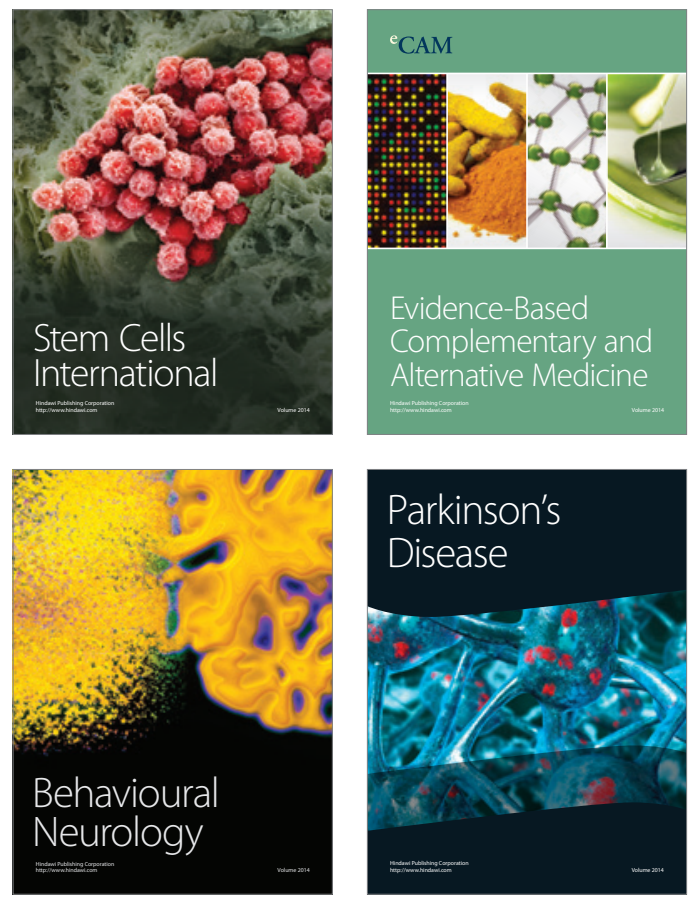
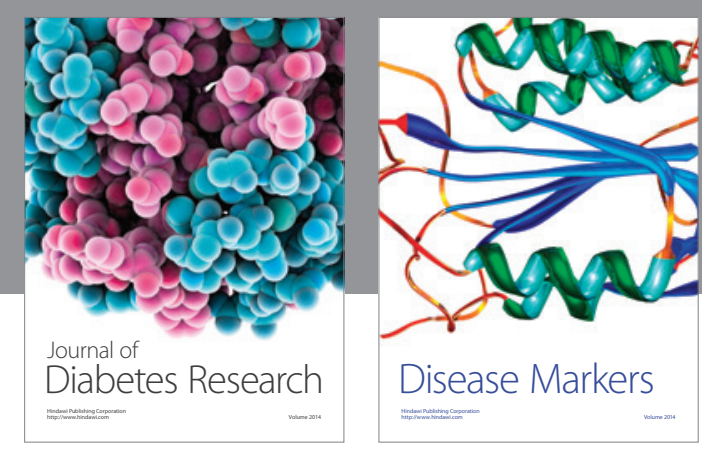

Disease Markers
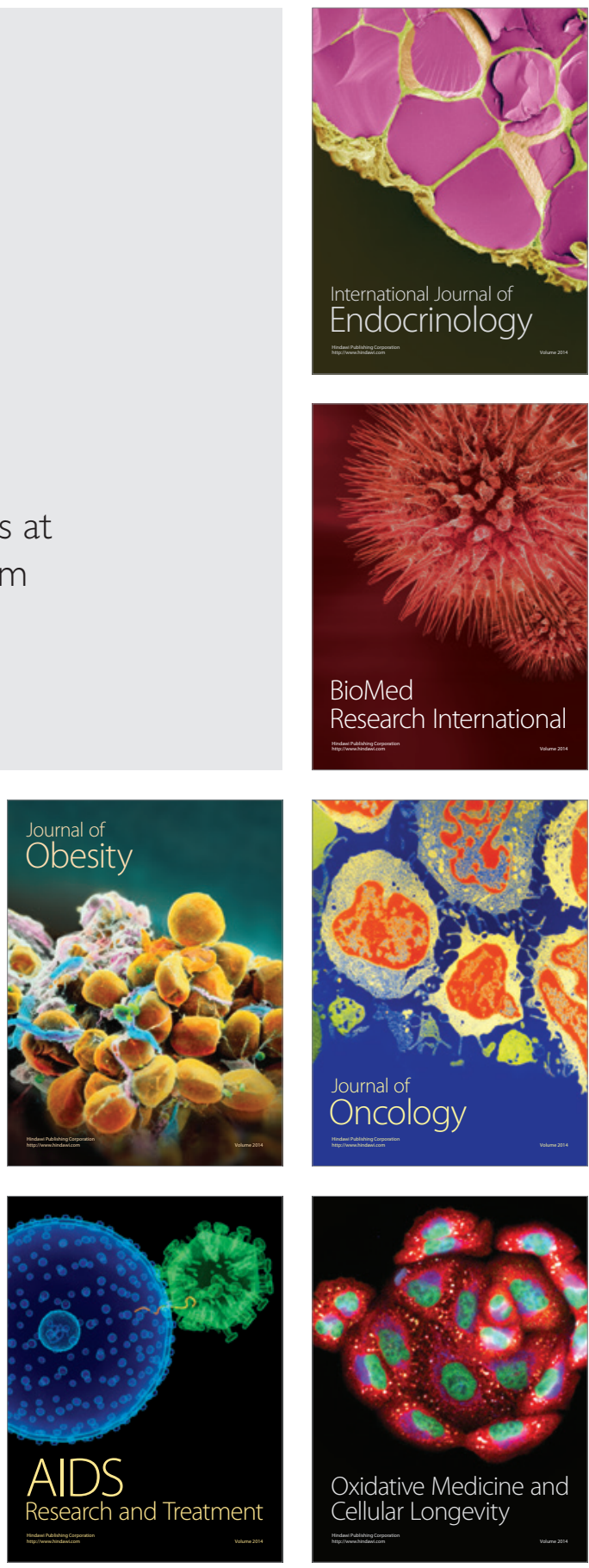